\title{
Comparing the Argumentum Model of Topics to Other Contemporary Approaches to Argument Schemes: The Procedural and Material Components
}

\author{
Eddo Rigotti • Sara Greco Morasso
}

Published online: 18 August 2010

(C) Springer Science+Business Media B.V. 2010

\begin{abstract}
This paper focuses on the inferential configuration of arguments, generally referred to as argument scheme. After outlining our approach, denominated Argumentum Model of Topics (AMT, see Rigotti and Greco Morasso 2006, 2009; Rigotti 2006, 2008, 2009), we compare it to other modern and contemporary approaches, to eventually illustrate some advantages offered by it. In spite of the evident connection with the tradition of topics, emerging also from AMT's denomination, its involvement in the contemporary dialogue on argument schemes should not be overlooked. The model builds in particular on the theoretical and methodological perspective of pragma-dialectics in its extended version, reconciling dialectic and rhetoric; nevertheless, it also takes into account numerous other contributions to the study of argument schemes. Aiming at a representation of argument schemes able to monitor the inferential cohesion and completeness of arguments, AMT focuses on two components of argument scheme that could be distinguished, readapting pragma-dialectical terms, as procedural and material respectively. The procedural component is based on the semantic-ontological structure, which generates the inferential connection from which the logical form of the argument is derived. The material component integrates into the argument scheme the implicit and explicit premises bound to the contextual common ground (Rigotti 2006). In this paper, the comparison of the AMT to other approaches focuses on the inferential configuration of arguments and not on the typologies of
\end{abstract}

\footnotetext{
E. Rigotti $(\bowtie) \cdot$ S. Greco Morasso

Institute of Linguistics and Semiotics, University of Lugano, via G. Buffi 13, 6900 Lugano, Switzerland

e-mail: eddo.rigotti@usi.ch

S. Greco Morasso

e-mail: sara.greco@usi.ch

S. Greco Morasso

Institute of Psychology and Education, University of Neuchâtel, Neuchâtel, Switzerland
} 
argument schemes and on the principles they are based on, which the authors intend to tackle in a further paper.

Keywords Argument scheme - Topics - Loci - Material starting point - Procedural starting point $\cdot$ Semantic analysis $\cdot$ Argumentum Model of Topics

\section{Objectives}

This paper aims to define the inferential configuration of arguments, ${ }^{1}$ namely to illustrate the structure of reasoning that underlies the connection between a standpoint and its supporting arguments. In other words, this is a paper dealing with argument schemes, which "reveal the internal structure of a single argumentation" (Van Eemeren and Garssen 2009: xvi). In order to reach this aim, we start discussing the interconnected notions of argument schemes and topoi/loci (Sect. 2), whose connections are still opaque in the current studies on this subject.

In the following of the paper, we provide an interpretation of the inferential configuration of arguments. In Sect. 3, we properly describe our theoretical and methodological proposal (the Argumentum Model of Topics, henceforth AMT), claiming that it provides an adequate approach to the understanding of the inferential configuration of arguments. Section 3.1.1. represents a sort of digression showing the relevance of semantic analysis to a proper theorization of argument schemes. After having outlined the main characteristics of the AMT, this proposal is compared with other modern and contemporary approaches to argument schemes (Sect. 4). Eventually, the reasons to adopt the AMT that have emerged throughout the present analysis are briefly highlighted (Sect. 5). Section 6 stands as a "programmatic conclusion", in which some items from our ongoing research inspired by the AMT are outlined.

\section{The Notion of Argument Scheme}

\subsection{Argument Schemes as Inferential Principles}

In order to clarify the AMT's contribution to the modern discussion of argument schemes, our first step is to clarify the sometimes uncertain notion of argument scheme itself and its relation to the more ancient concept of topoi/loci, which covers a partially overlapping yet distinct area.

Now, even though a certain number of substantial differences in the study of the inferential configuration of arguments can be found among modern and contemporary theories of argument schemes (see Garssen 2001 for an informative

\footnotetext{
1 Surprisingly, a term that has been so long meditated as argument may hide ambiguities. Its meaning proves to oscillate, even in contemporary authors, between: (1) textual manifestation - as a rule, partial from which the analytical reconstruction elicits the set of premises; and (2) actual argumentative move (a single argumentation). Here, the second meaning is intended.
} 
overview) as well as within the ancient and medieval tradition of the study of topoi/ loci (de Pater 1965; Green-Pedersen 1984; Braet 2004, 2005; Rigotti 2008), some common problems and some points of agreement in their solution can be identified. In this paper, we focus in particular on the modern approaches, the discussion of traditional contributions having been tackled elsewhere (Rigotti 2008).

There is wide agreement on the fact that argument schemes are somewhat abstract structures or forms to which the actual arguments can be ascribed. Perelman and Olbrechts-Tyteca (1958) are probably the first to use the term argument scheme, which is currently widely assumed (see Garssen 2001: 81); Argument scheme is translated into German with Muster (Argumentationsmuster) by Kienpointner (1992). Walton et al (2008: 1) define argumentation schemes as "forms of argument (structures of inference) that represent structures of common types of arguments used in everyday discourse" (emphasis added).

More precisely, the pragma-dialectical approach defines the argument scheme as "a representation of the pragmatic principle of support that is used when in the argumentation a reason is advanced for accepting a standpoint" (van Eemeren and Garssen 2009: xvi). The scheme is conceived of as a principle that allows studying the inferential soundness of arguments; in other words, a principle that allows moving from the argument premises to its conclusion, or, conversely but equivalently, from the standpoint to the argument supporting it.

\subsection{Argument Schemes and Loci: A Relation in Need for Clarification}

Despite the above outlined agreement on a basic definition of argument schemes, a certain degree of ambiguity is retrievable when one deals with precise definitions of argument schemes and their relation to the inferential configuration of arguments. As shown by Rigotti (2008), the ambiguity in the definition of argument schemes could be retraced to Aristotle and it surely reappears in modern approaches. Some of the problems concern the way the inferential configuration of arguments is constructed and the degree of specification of the analysis. In this relation, the common custom of listing numerous examples of arguments and argument schemes in order to construct exhaustive typologies, if not accompanied by a precise analysis, is not always of use in establishing precise criteria to define the real constituents of the inferential configuration of arguments. To quote an example, in Perelman and Olbrechts-Tyteca's (1958: 115) typology of loci (lieux argumentatifs) based on quantity, we find instances of premises that seem logical principles or inferential connections (like "the good which is useful towards a larger number of goals is preferable to that which is not useful to the same degree"), and examples of real and complete argumentations (ibid. ${ }^{2}$ ). These examples, clearly of a different nature, result simply listed, without systematic attention being paid to distinguish whether they are instances of loci, of principles of support, or even real arguments founded on a specific locus.

\footnotetext{
${ }^{2}$ See the original example in Perelman and Olbrechts-Tyteca (1958: 115), who declare to report the argument by which Timon highlights the value of pamphlets: "L'orateur parle aux députés, le publiciste aux hommes d'état, le journal à ses abonnés, le Pamphlet à tout le monde... Où le livre ne pénètre pas, le journal arrive. Où le journal n'arrive pas, le pamphlet circule".
} 
At a closer look, the main source of ambiguity in contemporary approaches to argument schemes is connected to the relation between the traditional notion of loci and argument schemes themselves. We will clarify our approach to this distinction below (see Sect. 3). For the moment, we just point to the treatment of the relation between these two different but at least historically related notions in modern argumentation studies.

First, it is interesting to remark that some contemporary authors simply avoid taking a clear-cut position on this matter:

Are schemes the same as topics, or would it be a mistake to try to fit Aristotle's Greek notion of the topos into the modern theory of argument schemes? Certainly, whatever one might say here, the topoi are the historical forerunners of the schemes (Walton et al. 2008: 276).

Other authors have approached the problem more directly. Particularly illuminating in this respect is Kienpointner's approach (1992: 194). In his critical observations to Perelman and Olbrechts-Tyteca, Kienpointner remarks that loci only constitute one of the components of argument schemes: they represent the "inhaltliche Schlußregeln" (content-bound inferential rules) that justify the passage from the argument to the conclusion. The inferential force is inherited by the argument insofar as it is an instance or "imitation" of a class of arguments defined by the inferential connection (inhaltliche Schlußregel). And, although these inferential connections constitute possible subjects of a classification, they should not be confused with argument schemes. Braet (2005: 66) makes a similar remark, identifying the topical principles of Aristotle's Rhetoric with "the core of a modern argumentation scheme". However, Kienpointner's approach can be criticized in relation to the overlapping between inferential connections (Schlussregel) and proper loci. Do loci and inferential connections really coincide? As Rigotti (2008) has shown, this is not the case, since from each locus several inferential connections (called maximae propositiones and later simply maximae in the Medieval tradition, a term maintained with maxims in the AMT) can be derived. There is thus a one-tomany relation between locus and maxims as, by the way, implicitly emerges also from the analyses proposed by Kienpointner: for example, he derives four inferential connections (maxims) from the locus from definition (Kienpointner 1992: 250-251).

\subsection{The Validity of Argument Schemes: An Evaluative Problem}

Another question that emerges as significant in relation to the definition of argument schemes is whether all the inferential connections at work in argument schemes have equal validity; several approaches maintain that this is not the case, and that, as a consequence, the inferential strength of arguments may significantly vary, depending on the force of the underlying inferential connection. Walton et al. (2008: 307) declare that "some [loci] are based on logical-semantic properties and are necessarily true; others are only plausible". This indirectly suggests that, in order to verify the hold of the argument schemes, one has to analyze in depth the semantic structure of the inferential connections (maxims) on which they are based. In fact, a 
careful semantic analysis helps identifying the conditions of validity of these connections. Van Eemeren and Grootendorst (1999) and Rigotti (2008) have provided relevant examples in this direction (see Sect. 3.1.1.).

\section{The Argumentum Model of Topics}

In relation to the ambiguities and open questions pointed out above, the Argumentum Model of Topics (AMT) aims at proposing a coherent and founded approach to the study of argument schemes, which can overcome these difficulties, yet being in line with previous achievements on this aspect. In this section, we will outline the main elements of our proposal.

As shown in Sect. 2.1, in general, modern authors conceive of argument schemes as the whole bearing structures that connect the premises to the standpoint or conclusion in a piece of real argumentation. In Garssen's (2001: 81) words (but see also van Eemeren and Grootendorst 1992 and van Eemeren and Garssen 2009):

The link between the argument and the standpoint is appropriate if the acceptability of the premise is "transferred" to the standpoint by means of the "argument scheme" that is being used.

We argue that the completeness of this "transfer" is not exclusively entrusted to the logical-inferential dimension of maxims. In this relation, we suggest to re-read the distinction proposed by the pragma-dialectical approach between procedural and material starting points in the opening stage (Houtlosser 2002: 20); we take the liberty of applying it as an instrument to specify how, in argument schemes, there is a dimension overcoming the logical principle. We argue that the argument scheme ${ }^{3}$ combines a procedural starting point, coinciding with the inferential connection (maxim) that is activated, with a material starting point guaranteeing for the applicability of the maxim to the actual situation considered in the argument. In other words, we propose to apply the notions of material and procedural starting points to identify the different nature of premises at work in the argument scheme. The precise reconstruction of these different types of premises and, so to say, the "discovery" of their intertwining connection is one of the main tenets of the AMT (Rigotti 2006).

In what follows, our effort will firstly aim at bringing to light the type of premises constituting the procedural starting point; then it will focus on the types of premises constituting the material starting point.

\subsection{The Procedural Component}

As regards the procedural starting point, according to the AMT, three levels emerge in the relation between loci and the entire argument schemes.

\footnotetext{
${ }^{3}$ Not coincidentally, the argument scheme, inasmuch as it connects the premises to the standpoint, though being a typical constituent of the argumentation stage, also plays a relevant role in the opening stage as for the premises evoked to support the standpoint.
} 
First level-It is represented by the locus itself, as the source from which arguments are taken: "unde argumenta ducuntur", to put it with Cicero (see Reinhardt 2003) or, according to the Medieval tradition, the habitudo, ${ }^{4}$ a term that can be properly interpreted as the "ontological ${ }^{5}$ relation" on which a certain argumentative reasoning is based. Consider the relationship between definiendum and definitum, the cause-effect relationship, the analogy (comparability) relationship, and so on. Such ontological relations are evoked by the names of the loci themselves: one speaks for example of the locus ex auctoritate, or of the locus $a b$ oppositis, and so on, nowadays translated into English with the expression "argument from" (from authority, from opposition).

Yet, merely quoting the name of a locus, does not show how the ontological relation determines the inferential configuration of arguments. In order to explain this, beyond the locus, the AMT integrates the analysis of their inferential configuration with two further levels.

Second level-Each ontological relation gives rise to a series of inferential connections called maxims. For example, the locus from the final cause (see Rigotti 2008) presents a series of possible maxims each of which gives rise to a subclass of possible arguments. Consider the following examples of maxims:

\footnotetext{
${ }^{4}$ In our first works on topics (Rigotti and Greco Morasso 2006; Rigotti 2006), we introduced the notion of hooking point to indicate the link between the argument and the standpoint. Later on, revising the medieval treatises on topics, the notion of habitudo has emerged as particularly insightful. The difference, though not substantial, is significant, as assuming the notion of habitudo means assuming a different focus. In fact, the notion of hooking point left implicit the relationship (between the world of the standpoint and the world of the argument) and only focused on one relatum, while habitudo highlights the relationship itself, thus involving both relata. The habitudo, by the way, turns out to precisely coincide with the locus.

5 The traditional philosophical concept of ontology was meant to deal with questions concerning what entities exist or at what conditions they can be said to exist, and how such entities can be grouped, related within a hierarchy, and subdivided according to similarities and differences (for example, by means of a tool like the Porphyry's tree, see Rigotti and Greco Morasso 2006). For the AMT, the term "ontological" builds on the following three notions: (1) "ontology of social reality" (Searle 1995), meaning a network of (institutionalized) commitments that create specific interaction fields (see also Rigotti and Rocci 2006); (2) ontology as it is understood within computer science and information science, i.e. a formal representation of a set of concepts within a domain and the relationships between those concepts, that may be used to define the domain and to reason about its (constitutive) properties; (3) the notion of ontology entailed by linguistic semantics, which is particularly relevant for the AMT. The role of ontology in semantics has been discussed in depth in Jackendoff (1983, 1990). Indeed, dealing, for instance, with the problem of reference, natural language semantics needs to postulate an ontology of some sort. Model-theoretic semantics postulate a very sparse formal ontology featuring only individuals, sets and worlds. It can however be questioned whether such an ontology is fully adequate for natural language semantics. The study of referential expressions shows that language(s) seem to require very specific "ontological presuppositions" (Jackendoff 1983) or "metaphysical assumptions" (Bach 1981: 79). For instance, natural languages force us to recognize things such as events, to set them apart from states, and cut even finer distinctions between different types of events (Vendler 1957; Bach 1981). Early linguistic contributions such as Whorf (1997 [1956])—on Hopi vs. English metaphysics—had seen this basic commonsense ontology as eminently culture and language specific, but most contemporary semanticists would maintain with Bach (1981) that at the level of the most basic 'world furnishing' we are interested in the commonsense ontology that is inter-culturally shared and is primarily bound to our common experience of the world.
} 
1. If a certain goal is to be achieved, it is reasonable to activate a causal chain allowing to reach it

2. If no causal chain is available, the goal cannot be achieved

3. If a certain behavior is not oriented towards a goal (as it cannot be considered a proper human action), it cannot be endowed with any property typically congruous (Rigotti and Rocci 2001) with human action (responsibility, merit, guilt and so on).

Third level-Each of these maxims activates a logical form, ${ }^{6}$ such as the modus ponens or the modus tollens. More specifically, provided that a certain ontological relation is the case, any inferential connection or maxim generated by it activates through its application a logical form in an argument scheme. For example, the maxim "if the cause is the case, the effect is too" activates the logical form of modus ponens. Different maxims may activate identical or different logical forms. Thus, when the locus from genus and species is instantiated, the maxim "what holds for the genus, holds for the species too" analogously activates a modus ponens. ${ }^{7}$ But, going back to the locus from cause and effect, the questionable maxim "if the effect is the case, the cause is too" activates the logical form of "false" modus ponens, which is usual in symptomatic argumentation. ${ }^{8}$ Another maxim pertaining to the same locus, "if the effect does not take place, the cause does not either" activates the logical form of modus tollens. Moreover, if the locus from immediate opposites is instantiated and $\mathrm{p}$ and $\mathrm{q}$ are immediate opposites, the maxim arises "if one opposite is the case the other is not", which activates the logical form of an exclusive disjunction.

In our view, these three levels give an accurate description of the procedural starting point of argument schemes.

\subsubsection{From Semantic-Ontological Structures (Loci) to Inferential Connections (Maxims)}

As remarked in Sect. 2.3, not all principles (inferential connections or maxims) at work in argument schemes are equally sound. Their soundness can only be inferred through a careful semantic analysis. For this reason, in this section, we will describe to what extent semantic analysis is required to understand and evaluate the

\footnotetext{
${ }^{6}$ In this relation the terminology adopted by logicians is oscillating: Layman (2002: $20 \mathrm{ff}$.) uses the term "argument form", Haack (1978: 201), Barth and Krabbe (1982: 156), Hughes and Cresswell (1996: 25), Epstein (2001: 196) use the term "rule" (e.g.: rule of modus ponens).

7 Compare Braet (2005: 66): “The topical principles from the Rhetoric [by Aristotle] will be regarded as the core of a modern argumentation scheme. For example the principle 'If the cause is present, the effect must occur' (Rhetoric 2.23.25) forms the if-then statement in the causal argumentation scheme 'If the cause is present, the effect must occur; well then, the cause is present, therefore the effect will occur'".

${ }^{8}$ In fact, the symptomatic argument, very common in all forms of explanation (for example, in the formulation of medical diagnoses), starts from the ontological relation connecting an effect to its (possible) cause. The relation between effect and cause is normally not necessary, since the same effect might be produced by different causes. Yet, ideally, what a good symptomatic argument should do is to identify the most probable (ideally the unique) cause for a given effect.
} 
procedural component of argument schemes and, in particular, the locus-maxim connection.

In general, the relevance of semantic analysis in solving polysemy is largely acknowledged and brings us to consider it as a relevant instrument for the analytical reconstruction of argumentation (van Eemeren and Grootendorst 2004), in particular to reconstruct implicit premises (Rocci 2008), and as a tool to unmask fallacies that are largely bound to semantic vagueness (as Aristotle remarked in the first book of his Topics and in the Sophistical refutations, see Ross 1958).

But, as mentioned, there is a more specific reason why we focus on semantic analysis here: semantic analysis is required to understand the proper nature of argument schemes; in particular, in order to highlight the way by which each locus generates its maxims. A maxim (or inferential connection) from which an argument scheme moves is an entailment connecting two or more factors of the same ontological relation, as pointed out by Rigotti (2008): for example, "If the cause takes place, the effect does too" is one of the maxims generated by the ontological relation "cause-to-effect", beside others like "If the effect is not the case, the cause is not either". As said, different ontological relations (the whole and its parts; causeto-effect; alternativity; the action and its purposes, etc.) properly correspond to loci. ${ }^{9}$ Loci guarantee the anchoring of reasoning to the semantic-ontological dimension; but they do not directly constitute a component of the inferential configuration of arguments: they figure in it as presupposed by the maxims that they generate.

Now, maxims are not mere rules, as they work as a particular type of premises, close to axioms. ${ }^{10}$ In order to study how maxims work and to what extent they are valid, a fine and detailed semantic analysis is needed.

In this regard, we start by considering a relevant methodological suggestion offered by van Eemeren and Grootendorst in their article "The fallacy from composition and division" (1999). In that paper, a thorough semantic analysis of the whole-parts relation, which specifies the categories of properties that are transferable or non-transferable from the whole to the parts and vice versa, allows to define the proper interpretation under which the concerned argument scheme is valid.

In particular, their analysis shows that not all properties (predicates) can be transferred from the parts to the whole and viceversa. The transferability of predicates depends on their semantic nature: structure-dependent properties are not transferable and, among the structure-independent properties, only the absolutenon-relative-properties ${ }^{11}$ can be transferred. In fact, all structure-dependent properties characterize the whole from various points of view in its wholeness: for its form (round or rectangular) or for its "functional" qualities (edible,

\footnotetext{
${ }^{9}$ In other words, a locus is constituted by a class of maxims generated by the same ontological relation.

${ }^{10}$ Maxims as such are by definition true. Rigotti (2008) introduces the term paramaxims to indicate those tentative or pretended maxims that, as they are false, cannot properly be considered maxims.

11 Structure-dependency presupposes a distinction between structured and unstructured wholes. Hamblin (1970) introduces an analogous distinction between physical and functional collections. Peter of Spain (Summulae Logicales, 5.7;5.14-5.23; in particular 5.14-5.18) analogously distinguishes between totum universale and totum integrale. Interesting remarks are put fore by Buridan (Summulae de dialectica 6.4.2 ss., see Klima 2002).
} 
poisonous, expansive, tasty, strong, coherent). As regards the relative structureindependent properties like heavy, light, fat, big, their non-transferability depends on the fact that they involve the whole not focusing on its structure, but implicitly comparing it with other entities considered under the same point of view; thus their scope involves the concerned reality in its wholeness: a big heap of light things (say of hay) may be intolerably heavy.

By means of this careful analysis of the conceptual system inhering to the wholepart relation, van Eemeren and Grootendorst show that precise semantic conditions must be met in order to ensure the validity of maxims. ${ }^{12}$ Another example of how semantic analysis helps identify the different maxims that can be derived from loci is presented by Rigotti (2008), devoted to the locus from the final cause, a locus used in pragmatic argumentation, belonging to the category of the causal argument scheme (van Eemeren and Grootendorst 1992). Rigotti's paper is concerned with the analysis of different maxims that can be derived from the ontological relation binding an action to its goal (final cause). It is interesting to remark how the various maxims that can be activated and their evaluation can be derived from a semantic representation (a sketched "ontology") of the human action. Action is characterized as an event intentionally caused by a human subject who, being aware of the present situation and of a new possible comparatively more convenient state of affairs, which can be realized through a causal chain available to him/her, is attracted by this new, possible, state of affairs and, making the decision of applying the causal chain, activates it, thus realizing his/her purpose. Often, many different, not strictly constitutive factors become relevant in the decision or realization of an action: given the situated nature of decision making, different competitive desires and different costs of the causal chain may induce the agent to abandon or substantially change his/her purpose; the degree of adequacy of the causal chain may show to be insufficient and transform the action into an unhappy attempt; the possible positive or negative side effects, including the informative and relational implications of action, the possible presence in the causal chain of subservient instrumental actions and the quality of their ends and of their possible side effects, may convert the action into a complex and hardly manageable process, in which the human subject intensively "negotiates" the realization of its purposes with the surrounding context.

The elicitation of the semantic constituents of a human action allows Rigotti (2008) to illustrate and subsequently evaluate a series of maxims bound to the locus from the final cause (in particular, the strict conditions of applicability of the principle "the end justifies the means").

Both papers we have mentioned show that semantic investigation proves to be a necessary prerequisite to the elaboration of a theory of argument schemes, useful in particular in relation to understand which specific maxims can be correctly activated in argument schemes. Semantic analysis could for example also provide a distinction between the notions of action and event, thus allowing to evaluate the locus from the efficient cause. The different types of oppositions called upon in the

\footnotetext{
12 In this relation, we hypothesize that the fallacious or sound use of argument schemes is often not determined by their presumptive or probabilistic nature, but by an uncertain definition of their conditions of semantic applicability.
} 
locus from opposition, such as contradiction or mediata and immediata contrary terms ${ }^{13}$ can also be profitably distinguished from the semantic point of view. Semantic analysis, thus, offers a tool to fill the gap between the research on topics (ontological relations) and the research on argument schemes actually used in reallife argumentative discourse, as it allows formulating the relation between locus and maxims. Moreover, semantic analysis allows a careful evaluation of the maxims applied as premises in actual argument schemes. For these reasons, semantic analysis is integrated into the AMT (Rigotti and Greco Morasso 2006).

\subsection{The Material Component and its Intertwining with the Procedural Component}

We have already remarked that, according to the AMT, the procedural component is not sufficient for a complete reconstruction of argument schemes. Indeed, argument schemes claim to account for the relation between real arguments used in real-life discussions and real standpoints they support; therefore, beyond the procedural starting point now reconstructed, we also have to shed some light on what we propose to consider a specific "material starting point" that is invoked to complete the inferential process and, at the same time, to enhance the persuasiveness of arguments based on these argument schemes (Rocci 2006). ${ }^{14}$ In fact, the validity of the maxim is a necessary, not a sufficient condition for the soundness of an argumentative move: another level of premises must be taken into account (Rigotti and Greco Morasso 2006; Rigotti 2006, 2008; Rigotti and Greco Morasso 2009). We claim that the AMT, beyond specifying the various levels that should be taken into account in the reconstruction of argument schemes, also allows accounting for the material starting point that is inherent to them in real occurrences of arguments.

Let us take as an example the argument scheme from analogy, analyzed by van Eemeren and Grootendorst (1992), van Eemeren, Grootendorst and SnoeckHenkemans (2002: 99) and Van Eemeren et al. (2007: 138) as follows:

1. $\mathrm{Y}$ is true of $\mathrm{X}$

2. Because $Y$ is true of $Z$

3. And $\mathrm{Z}$ is comparable to $\mathrm{X}$

This argument scheme builds on the analogy of two comparable entities ( $\mathrm{X}$ and $\mathrm{Z}$ ), which is assumed as a premise to reach the conclusion that a property (Y)

\footnotetext{
${ }^{13}$ Here, it is first of all important to distinguish between contrary terms and contradictory terms (see in this relation the discussion in Petri Hispani Summulae logicales 3.32, cf. Bochenski 1947: 33). Moreover, even concerning contrary terms, already Aristotle, in his Categoriae, observed that contrary terms not necessarily are the opposite poles of a dichotomy, like odd and even numbers. In some cases, contraries admit intermediate terms, as in the case of white and black, which admit an infinite set of grey shades in between. This has been developed in the medieval doctrine of oppositions, which distinguished among contraria mediata (which admit some intermediate terms) and immediata (see Gatti 2000: 33).

${ }^{14}$ Persuasiveness, indeed, is not exclusively based on the validity of a procedure. To put it synthetically, it is rooted on how much the actual arguments used are anchored in the "material" common ground of the participants in the critical discussion (Rigotti 2006). In this sense, a further component in the reconstruction of the inferential structure of arguments has to be included, accounting for this "aboutness" of the actual use of argument schemes.
} 


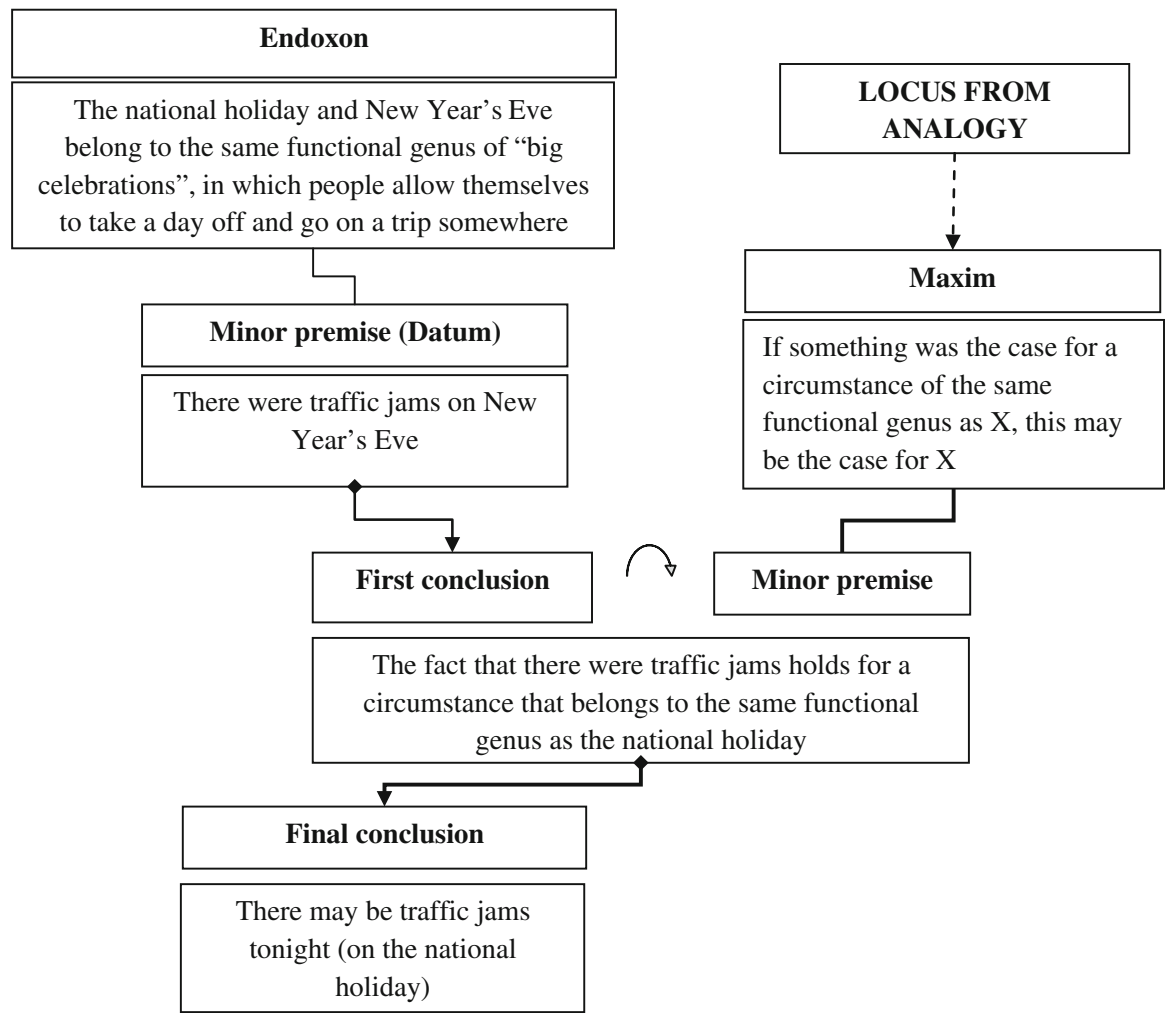

Fig. 1 AMT's synergic representation of the New Year's Eve-national holiday analogy argument

inhering to one of the two comparable entities (Z) should therefore also inhere to the other one (X). Clearly, the whole reasoning from the premises to the conclusion is comprised by this representation of the argument scheme. An argument scheme, in fact, is expected to make the whole mechanism explicit which connects the premises to the standpoint. We claim that this type of analysis is helpful but not completely satisfactory as a means to understand what the real force of the argument is based on. Let us apply this analysis to an actual argument in order to show how an AMTbased analysis would account for all levels of the inferential configuration of the scheme while, at the same time, allowing to focus on the connection to its material starting points. Consider the following very ordinary argumentation:

A: Should we travel by train or by car?

B: Remember the traffic jams on New Year's Eve? And today is our national holiday!

Following the above mentioned pragma-dialectical characterization of the argument scheme, we have:

1. It is true of this evening (our national holiday) that there will be traffic jams.

2. Because the fact that there were traffic jams was true for New Year's Eve. 


\section{And the national holiday is comparable to New Year's Eve}

Now, it will emerge from our presentation that all elements put forward in the pragma-dialectical approach are accounted for within the AMT, which however explicitly includes further information. More in particular, the AMT is helpful in identifying the source of the force of the statement presented as an argument in relation to the statement presented as a standpoint; "the force that forces" us to acknowledge it is an argument in support of that specific standpoint.

Besides, the AMT introduces a representation focusing on the connection between the material and the procedural starting points.

Beginning with the procedural starting point, the three levels concerned may be summarized as follows:

- First level-Semantic-ontological relation: Locus from analogy: the comparability between $\mathrm{X}$ and $\mathrm{Z}$ is based on their common belonging to the functional genus (Walton and Macagno 2009: 158) of "big celebrations", in which people allow themselves to take a day off and go on a trip somewhere;

- Second level-Inferential connection or maxim: If something has been the case for a circumstance of the same functional genus as $\mathrm{X}$, it may be the case for $\mathrm{X}$;

- Third level-Logical form of modus ponens: If something was the case for a circumstance of the same functional genus as X, this may also be the case for X; now, the presence of traffic jams was the case for a circumstance that belongs to the same functional genus as the national holiday; therefore it may also be the case for the national holiday, i.e. for tonight.

The logical form thus sketched is inferentially valid if all premises are true. However, the truth of the second premise incorporated in the logical form (third level) is not derivable from the maxim; it must be derived from outside, namely from material starting points. In other words, the truth of this premise must be provided some effectual backing belonging to the interlocutors' material common ground. This backing is necessary in order to exhaustively represent the inferential configuration of a real argument, since the maxim, in order to actually work, needs to be applied to an appropriate situation (Rigotti 2008). In this sense, the pragmadialectical account, as shown above, correctly identifies a necessary requirement that must be met in order to arrive at a complete description of an argument scheme: The national holiday and New Year's Eve must indeed be considered comparable circumstances. However, the comparability needs further backing. Following Walton and Macagno (2009: 158), we might say that, in our case, both celebrations are part of "a common functional genus"- that of "big celebrations", in which people allow themselves to take a day off and go on a trip somewhere. ${ }^{15}$

\footnotetext{
15 Interestingly, also in the case of the locus from analogy, semantic analysis should be invoked in order to identify the proper conditions of its validity, concerning in particular the notion of comparability and the connected notion of functional genus. Comparability, indeed, is not mechanically established: it holds if it focuses on a relevant dimension of the concerned property. For example, in this case, the two celebrations are not claimed to have the same meaning; they are comparable as to the behaviors they provoke. Or, in another domain, a Federal State can be compared to a family, since member States, like family members, are expected to help each other; but we could not say that, in a family-like manner, member States get old and die...
} 
The backing of the comparability is an actual premise of the argumentation; yet it does not consist in an inferential connection, but rather in an assumption based on the discussants' shared knowledge of the two considered celebrations. We could thus say that this is a typical instance of material starting point. In this connection, we propose to reconsider the Aristotelian notion of endoxon (Rigotti 2006, 2008; Tardini 1997):

Endoxa are opinions that are accepted by everyone or by the majority, or by the wise men (all of them or the majority, or by the most notable and illustrious of them) (Topics 100b.21).

An endoxon is thus an opinion that is accepted by the relevant public or by the opinion leaders of the relevant public. ${ }^{16}$ At a closer look, the notion of relevant public is very important because it turns out to coincide with the notion of audience (van Eemeren and Houtlosser 2002).

Now, the protagonist and antagonist in the concerned critical discussion must agree upon the material starting points in order to resolve their difference of opinion. In the case proposed above, it is up to them to accept the equivalence between the two celebrations. Still in connection with the material starting point, one has to add to the general premise represented by the endoxon also a factual premise, which is likely to be accepted if it corresponds to the repeated observations of the participants in the critical discussion: the fact that there actually were traffic jams on New Year's Eve. Following Toulmin, we call this premise of factual nature datum. From the logical point of view, the conjunction of the endoxon with the datum leads us to the conclusion ${ }^{17}$ that "The fact that there were traffic jams holds for a circumstance that belongs to the same functional genus as the national holiday". Such a "preliminary" conclusion derives from the material starting point;

\section{Footnote 15 continued}

Moreover, an adequate semantic analysis should distinguish, in connection with the different nature of the standpoints concerned, two main types of arguments from analogy: (1) arguments whose standpoints represent factual claims; (2) arguments whose standpoints represent evaluative claims. The maxims should be correspondingly specified: in the first type, the functional genus is justified by the emergence of the same cause (that may be more or less deterministic in nature) in the two compared states of affairs; in the second type, the functional genus is based on the applicability of the same criterion of evaluation. Our example clearly pertains to the first type of analogy. An example of the second type of argument from analogy would be: "the US Federal Government must assist the Detroit's automakers as Detroit is being hit by an economic hurricane just as New Orleans was hit by a natural hurricane (Katrina)".

${ }^{16}$ It seems that the tradition of topics indeed neglected the notion of endoxon, perhaps merging it with maxim. But it is hard to imagine that Aristotle attributed to all people or to the majority of them or to the wisest ones etc. the shared explicit knowledge (or belief) of topical rules, even though these rules may become part of the acquired outfit of some of them. The cognitive status of the abstract, general inference rules discovered by argumentation theorists cannot be interpreted in terms of the prevailingly shared opinion. The ignorance of this fundamental component of Aristotelian topics is probably due the fact that Aristotle did not explicitly give any example of what he understood by endoxon. Numerous endoxa can, however, be reconstructed from the examples often given by the author when listing his topoi. Not coincidentally, in our opinion, Braet, aiming to reconstruct an ideal model of an Aristotelian locus, lists as its fourth relevant component, beyond the name, the suggestion of a fair procedure for establishing the concerned type of argument and the topical principle involved, an actual example (in our opinion, inevitably including an endoxon) to which Aristotle often applies this principle (Braet 2005: 69).

${ }^{17}$ In this case, a categorial syllogism is activated. 
but it is equally exploited by the procedural starting point, being associated to the maxim as a minor premise (see Fig. 2).

This point of intersection is crucial in the perspective of the AMT: in fact, it represents the junction between the material and the procedural starting points and shows how different types of premises are combined in real argumentation. A graphical representation, named Y-structure, is meant to focus on this connection (Fig. 1; see also the examples in Rigotti 2006, 2009; Christopher Guerra 2008; Palmieri 2009; Filimon 2009; Danesi and Rocci 2009; Rigotti and Greco Morasso 2009; Greco Morasso 2009).

\section{Comparison to Other Approaches}

Any new proposal calls for justification. Therefore, after having outlined the theoretical proposal represented by the AMT, it is now time to go into detail in showing its critical advantages in comparison to other existing approaches to argument schemes. Generally speaking, we claim that the AMT is both more explicit and more complete in identifying the inferential configuration of arguments.

In comparing the AMT with other theoretical proposals, we shall not assume a holistic approach, i.e. we shall not compare the different models with respect to all their features; rather, we shall focus on one specific aspect, namely the inferential "mechanism" of arguments. Other aspects, such as the taxonomy of argument schemes, the context-boundness of endoxa and data or the logical and cultural boundness of keywords exploited in the material component, will not be considered. Our comparison will thus be declaredly partial as, in our opinion, it is more urgent to focus the discussion on a more punctual aspect of the AMT: its ability of bringing to light the inferential configuration of arguments, i.e. its ability of explaining and reconstructing the often complex, and generally implicit, inferential mechanism applied in argumentative discourse. In fact, if this comparison does not prove that the explanatory capacity of ATM at least equals, or possibly overcomes the capacity of other models, any further comparison would become useless; indeed, any effort to improve an instrument that has showed to fail in fulfilling its fundamental task would be rather unreasonable.

\subsection{Around 1958}

The Traité de l'argumentation by Perelman and Olbrechts-Tyteca (1958) devotes considerable attention to argumentation schemes as it presents, describes and exemplifies (often following the classical and the modern French rhetorical tradition) numerous topoi/loci, understood as links (liaisons ${ }^{18}$ ) to the standpoint and proposes a tripartite taxonomy of arguments (arguments quasilogiques, arguments basés sur la structure du réel, arguments qui fondent la structure du réel). However, while they propose an interesting criterion for classifying loci, these authors do not

\footnotetext{
18 It is interesting to observe that the term liaison seems to cover the Medieval notion of habitudo, albeit Perelman and Olbrechts-Tyteca seem to ignore the corresponding tradition.
} 
go into the details of the inferential configuration of argument schemes; their approach is thus not so relevant to our present goals.

Toulmin's contribution to the analysis of the inferential structure of arguments (see Toulmin 1958 in particular) is rather difficult to interpret, as the well-known "Toulmin model" is open to different interpretations, oscillating between a tool to describe an argumentation structure and a means to analyze the internal structure of a single argumentation. In the latter interpretation, the Warrant might perhaps be interpreted as the inferential principle (or maxim). In fact, although the equivalence between a Warrant and an inferential connection deriving from the locus is neither explicit nor justified in Toulmin, he declares that warrants are general patterns, "certifying the soundness of all arguments of the appropriate type" (Toulmin 1958: 100), while Toulmin et al. (1984: 199) use Warrants as the defining criterion for the classification of arguments. Moreover, Toulmin (1958) also introduces the concept of Datum as a factual premise. Generally speaking, however, Toulmin's approach does not result in a clear analysis of the inferential configuration of arguments.

Hastings, in his PhD dissertation (1962), focuses on Toulmin's notion of Warrant distinguishing three types of reasoning, namely verbal classification, causal reasoning and direct proof. For every argument scheme he specifies the semantic field of the premises, from which the reasoning starts and upon which it is grounded and the semantic field of the conclusion to which the reasoning moves. Moreover, he develops Toulmin's rebuttal into the notion of set of critical questions associated with each argument; indeed, a promising intuition that has later been developed in other approaches (see Garssen 2001; Walton et al. 2008; Christopher Guerra 2008).

\subsection{Kienpointner's Alltagslogik}

Manfred Kienpointner's contribution to the rediscovery of the topical tradition is, in our opinion, particularly relevant. In particular, Kienpointner (1997) focuses on a heuristic reading of topics and proposes its integration not only with the ancient status theory, but also with several modern techniques of argument invention (debate theory, encyclopedic systems, creativity techniques). For both aspects- the rediscovery and re-appreciation of the topical tradition and the focus on a heuristic exploitation of topics, Kienpointner's contribution proves to be significant not only for interpreting the tradition, but also for actualizing it. In particular, he highlights the relation between loci and argument schemes (see Sect. 1). Specifically, the inferential configuration of arguments is presented by Kienpointner (1992: 274, see Table 1) in relation to the argument scheme from the whole to the parts:

Now, as already remarked in Sect. 2.2, Kienpointner's approach ensures significant advantages insofar as it explicitly formulates maxims. However, how maxims inferentially support actual arguments remains unclear. In Kienpointner's account, maxims are stated and actual arguments are juxtaposed as examples; but their "interaction" is not made explicit. Not by chance, the conditional with which the example reported in Table 1 starts ("If the countries...") is not really justified by the maxim, even though it reproduces its syntactic structure. In order to become inferentially relevant, the same premise should be "Countries and their inhabitants correspond to a whole and its parts respectively". However, the latter is a rather 
Table 1 Reconstruction of Kienpointner's account of the inferential configuration of arguments

Scheme from the whole to the parts

What is asserted of the whole, is asserted of the parts too

$\mathrm{X}$ [poverty] is asserted of the whole [the countries]

Therefore: $\mathrm{X}$ is asserted of the parts [the inhabitants]
If the countries of the third world are poor, their inhabitants are generally poor too

[These countries are poor]

Therefore: their inhabitants are generally poor

questionable premise, which determines the evident weakness of this argumentative move. A further premise, which is omitted in Kienpointner's reconstruction, but which needs to be added for reasons of inferential consistency, is: "These countries (of the third world) are poor".

But, were this integrated reconstruction accepted, Kienpointner's approach would come to coincide with the AMT. We can thus conclude that, in relation to Kienpointner's proposal, the AMT turns out to be not only more complete, but also more precise in formulating which kind of premises and inferential links between them are necessary for the argument to be sound.

\subsection{Walton, Reed and Macagno}

Douglas Walton is certainly to be mentioned here for the attention he has devoted to the inferential configuration of arguments in relation to a very numerous set of argument schemes. ${ }^{19}$ His approach to argument schemes has recently been systematized in Walton et al. (2008), also with the integration of the graphical representation allowed by the argument visualization software Araucaria. Here, it is worth considering some of the examples proposed in this and in some preceding work, in order to highlight the components that Walton and colleagues consider relevant to describe the inferential configuration of arguments. For example, in Walton (2005: 54) and in Walton et al. (2008: 310) the appeal to expert opinion is presented as in Table 2 .

Now, what is presented here as a conclusion does not properly follow (non sequitur) from the premises explicitly indicated. On the basis of such premises, we can only conclude that "A, belonging to subject domain $\mathrm{S}$, is asserted by an expert

Table 2 Reconstruction of the argumentation scheme from expert opinion according to Walton

Argumentation scheme from expert opinion

\begin{tabular}{ll} 
Major premise & E is an expert in subject domain S containing proposition A \\
Minor premise & E asserts that proposition A (in domain S) is true (false) \\
Conclusion & A may plausibly be taken to be true (false) \\
\hline
\end{tabular}

\footnotetext{
${ }^{19}$ For reasons of uniformity, we here adopt the phrase «argument scheme»; Walton and colleagues, however, prefer "argumentation scheme".
} 
in this subject domain". A considerably more complex inferential structure is required in order to obtain the desired conclusion. What appears to be lacking here is, in fact, the inferential connection, or maxim, justifying the whole reasoning: "If a proposition A is asserted to be true by an expert of the field to which A belongs, then A may plausibly be taken to be true". The two propositions presented by Walton as premises allow us to infer only this provisional conclusion: "A, belonging to subject domain $\mathrm{S}$, is asserted to be true by an expert in this subject domain". We might thus say that this account seems to privilege the material starting point of argument schemes, by highlighting the endoxon and datum (major and minor premise, respectively), but it fails to signal how these important components are inferentially connected to the conclusion or standpoint. More generally, in the Araucaria representations of the inferential configuration of real-life arguments provided in Walton et al. (2008), the material starting point is present, while the maxim is not stated (see for example the argument scheme from verbal classification, p. 77; or, again, the argument scheme from expert opinion, p. 262).

Moreover, we may remark that the proposition "A, belonging to subject domain $\mathrm{S}$, is asserted to be true by an expert in this subject domain" corresponds to an instance of the proposition represented by the first component of the maxim introduced by "if": we expect that the final conclusion will coincide with an instance of the second component of the maxim (beginning with "then"). In fact the conjunction of the inferential connection (maxim) with this provisional conclusion legitimates us to eventually conclude with Walton that "A may plausibly be taken to be true". The whole inferential procedure may be summed up as represented in Table 3.

Yet, as a matter of fact, the required integrations make Walton's analysis coincide exactly with the one proposed by the AMT. In this respect, the AMT proves to make the inferential configuration of arguments more explicit and inferentially consistent.

Another example discussed in Walton (2006: 285) presents a more complex and intricate situation, which can analogously be solved by assuming some integrations offered by the AMT perspective.

The description in Table 4 can be considered an acceptable formulation of the argument, but certainly is not the analysis of its inferential configuration. In fact, the

Table 3 Interpretation of Walton's account of the argumentation scheme from expert opinion

MAXIM: If any proposition $p$ is asserted to be true by an expert in the field to which $p$ belongs, then $p$ may plausibly be taken to be true

MAJOR PREMISE: $E$ is an expert in subject domain $S$ containing proposition $A$.

MINOR PREMISE: $E$ asserts that proposition

$A$ (in domain $S$ ) is true (false).

PROVISIONAL CONCLUSION: (working as minor premise, associated to the maxim): $A$, belonging to subject domain $S$, is asserted by an expert in this subject domain

CONCLUSION: A may plausibly be taken to be true 
Table 4 Walton's representation of the argumentation scheme for the direct ad hominem argument
Argumentation Scheme for the direct ad hominem argument

The respondent is a person of bad (defective) character.

Therefore the respondent's argument should not be accepted.

Table 5 Interpretation of Walton's account of the argumentation scheme from expert opinion

(PARA)MAXIM: If an argument is used

by a person of bad character, it should not be accepted

PREMISE1: $\mathrm{X}$ is a person of bad character

PREMISE2: Argument $\mathrm{A}$ is used by $\mathrm{X}$

PROVISIONAL CONCLUSION: (Argument A is used by a person of bad character)

CONCLUSION: This argument should not be accepted

representation limits itself to utter the datum, ignoring the maxim, which could be reconstructed as: "If an argument is used by a person of bad character, it should not be accepted". This is, by the way, not a proper maxim but a fallacious principle-a paramaxim, in Rigotti's (2008) terms-which should be distinguished from the seemingly similar maxim used in the argument scheme from authority (in its destructive formulation): "If a statement is put forward by a person of bad character (or an unreliable person), it should not be accepted". In fact, even a person with a defective character can advance a good (valid) argument. Within the AMT, the same move would be reconstructed as in Table 5 .

In this case, the ATM-like representation allows making explicit all the components of the argument scheme. It also allows showing to what extent the non acceptability of the reasoning depends on the maxim. In more general terms, the analysis proposed by the AMT quasi-Y structure does not only provide a tool to analyze the inferential configuration of an argument; it also helps identify which nodes of the inferential structure are sound and which ones are not (Christopher Guerra 2008). Thanks to the explicit distinction between the material and the procedural component, it also allows to establish whether the possible faults of an argumentative move depend on the use of an invalid maxim or on a false, incorrect or partial anchoring to the arguers' material starting points.

\subsection{The Pragma-Dialectical Account to Argument Schemes}

We have already considered some specific aspects of the AMT in relation to the pragma-dialectical view of argument schemes in Sect. 3. However, it is worth briefly elaborating on the specific approach to the elicitation and representation of the inferential configuration of arguments. In particular we take into account van Eemeren and Grootendorst (1984, 2002), van Eemeren et al. (2002), Garssen (2001, 2009), and Van Eemeren et al. (2007). 
Going back to the example presented in Sect. 3.2., concerning argument from analogy, some considerations can be made on how the different constitutive components of argument schemes are treated in the pragma-dialectical account. The first level of the procedural component, namely the semantic-ontological relation singled out by the AMT could be retrieved in this account by the name of the argument scheme itself; not coincidentally, the authors also speak of symptomatic, analogical and causal relationship or relation (Garssen 2001: 92 ff). Van Eemeren et al. (2007: $138 \mathrm{ff}$.) focus on a series of sub-types of argument schemes, thereby suggesting that more specific ontological relations can be singled out than only the three, actually rather generic, categories mentioned above.

What we have called the second level or maxim in the AMT is not explicitly formulated in the general representation of the argument scheme in pragma-dialectics, despite some maxims are discussed in the discursive description of the different subtypes of argument schemes (van Eemeren et al. 2007: 137 ff; Garssen 2009). As a matter of fact, maxims are specific argumentative principles at work in concrete applications of argument schemes and, therefore, can only be identified within specific sub-types. For example, Garssen (2001: 92) states that there is a specific sub-type of argumentation from analogy based on the "principle of justice"; this principle, which could exactly be identified with a maxim in the AMT's terminology, "claims that people who are in similar situations should be treated similarly" (ibid.). These considerations give a picture of the pragma-dialectical approach to what we have called the procedural starting point of argument schemes. However, though largely compatible with the AMT, this approach results less systematic in the description of the inferential configuration of argument schemes.

In the case of analogy, van Eemeren et al. (Van Eemeren et al. 2002: 99, see Sect. 3) identify as premises of the argument scheme both a statement about the actual comparability of two entities " $\mathrm{Z}$ is comparable to $\mathrm{X}$ " (which is to be interpreted as an endoxon in AMT's terms) and the attribution of a certain characteristic to the entity that is assumed as a comparison term "Because Y is true of Z" (according to the AMT, a Datum, see Sect. 3.2.). The material component is thus somehow present in pragmadialectics, although the fact that these premises are different in nature from those pertaining to the procedural component is not explicitly singled out. To put it in more general terms, we might say that the AMT can provide an exhaustive representation of the argument scheme, which is kept partially implicit in the pragma-dialectical approach. In particular, the representation offered by the AMT has the advantage of requiring a precise identification of the maxim at work, as well as of making explicit the intersection between the procedural and the material starting points.

\subsection{Some Conclusions Suggested by the Comparison}

This very concise overview of different contributions offered so far to the study of argument schemes showed that, while many relevant aspects of argumentation schemes were considered in depth throughout these fifty years of intensive research in our discipline, the inner inferential structure of arguments was not studied adequately. Moreover, the overview presented in the preceding section shows that most approaches propose representations that, in order to become coherent (and 
Locus from...

Liaison (Perelman and Olbrechts-Tyteca 1958)

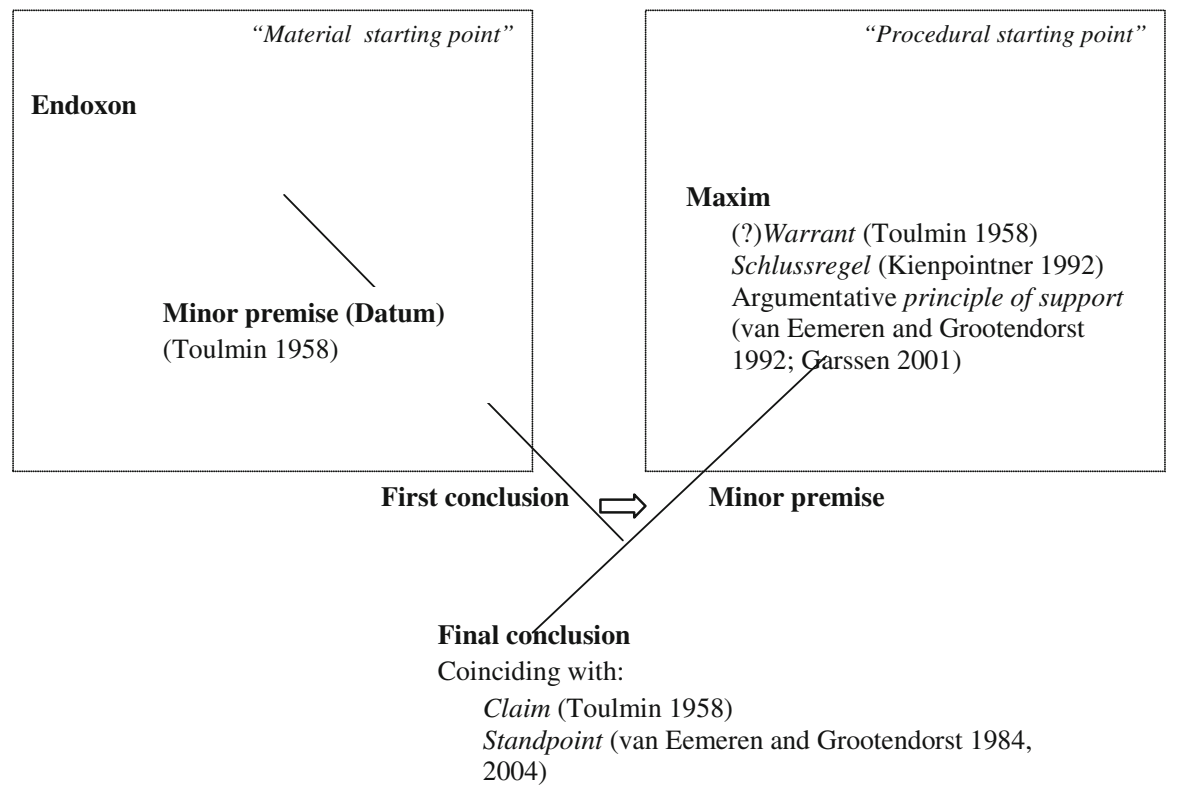

Fig. 2 How the AMT allows to interconnect essential components of argument schemes

sound), need to be significantly integrated by including further premises. And such integrations seem to translate these representations into the analysis of arguments proposed by the AMT.

In sum, we might say that the Y-like structure proposed by the AMT allows reunifying and connecting some elements that had previously been indicated as relevant in the study of argument schemes; as Fig. 2 shows, some areas of conceptual overlapping can be identified. Moreover, further elements necessary to understand the inferential configuration of arguments are exclusively specified by the AMT. What equally emerges from Fig. 2 is the opportunity offered by the AMT to highlight the inferential links between all these elements and, in particular, to focus on the intertwining between the procedural and the material starting points thanks to the "exploitation" of the First conclusion deriving from the endoxonbased line of reasoning as a minor premise in the maxim-based line of reasoning.

\section{Top Five Reasons for Adopting the AMT Perspective}

To sum up, four main reasons can be identified to adopt the AMT perspective as a tool for the analysis of the inferential configuration of arguments:

1. The inferential configuration of actual arguments is made more explicit;

2. The argument premises are identified in such a way that allows distinguishing the procedural premises from the material (endoxical) ones (see Sects. 3.2 and 
4) and focusing on the crossing point between the procedural and the material components (Sect. 4.5.).

3. The context-boundness of arguments is made evident (see also Rigotti 2006) by eliciting endoxon and datum within the material component of the argument scheme.

4. As Garssen (2001: 91) remarks, argument schemes can be distinguished "because each scheme comes with different critical questions". Walton, Reed and Macagno (2008: 3 and passim) also highlight the significance of critical questions to evaluate argument schemes. In this regard, the AMT can support the elicitation of the possible critical questions that are relevant for each node of the Y-structure (see Christopher Guerra 2008), specifying to exactly which node the validity problems of an argument are connected (see Sect. 4.3 for some indications).

More in particular, in relation to the approach that we consider as a general framework for the AMT, namely, pragma-dialectics, a substantial difference is to be found. It is true that the same standpoint can be inferred both from the premises reconstructed in the pragma-dialectical approach and from the Y reconstruction proposed by the AMT (see Sect. 3.2.) and thus, from this point of view, both proposals are plausible. However, the reconstruction of explicit and implicit premises proposed by pragma-dialectical theoreticians (van Eemeren and Grootendorst 1984, 1992, 2004) does not properly answer to the burden of proof imposed by the task of eliciting argument schemes. In fact, it does not highlight the foundation of the force of the argument in relation to the standpoint. In general, the pragma-dialectic account of argument schemes shows that the argumentstandpoint nexus is an instance (a token) of a class (a type) of argumentstandpoint pairs; such a nexus is active in all cases in which the conditions of the standpoint are realized. Let us analyze a simple example: The Mauritanians cannot have arms. They do not have iron ("Mauri non habent ferrum"). A pragma-dialectical reconstruction of this argumentation would sound like: "If there is no iron, there cannot be arms" (and the Mauritanians lack iron; therefore they cannot have arms)". In relation to the specific argument-standpoint pair considered in this example, the pragma-dialectical reconstruction of the premise ("If there is no iron, there cannot be arms") reconstructs a class of argumentative pairs that includes all cases in which the lack of iron hinders the production of arms (any time iron is lacking, arms are lacking). However, in this case as well as in the other possible ones, this reconstruction does not specify the reason why the lack of iron should actually hinder the production of arms. In the class of argumentative pairs based on the principle "no iron, no arms", the argumentstandpoint relation thus remains opaque.

To answer to this problem, the AMT reconstructs the inferential configuration of the argument on the basis of the relation between the product and its material cause. This is evoked in all actual instances of this "ontological relation" (iron/ arms, milk/butter, chocolate/Sachertorte, flour/bread, etc.) where specific endoxa can be activated: "Arms are made of iron", "Butter is made from milk", "Sachertorte is basically a chocolate cake", "Bread is a product of flour", etc.). More specifically, The AMT would split the premise "If there is no iron, there 
cannot be arms" into (1) a maxim founded on the locus from the material cause: "if the material cause is not present, the product cannot be present"; and (2) a material starting point, stating that "Iron is necessary to make arms" (endoxon) and "The Mauritanians lack iron" (datum). This reconstruction is more adequate in terms of showing what the force of the argument relies upon. In fact, it is precisely from the lack of the necessary material cause (iron) that the argumentation supporting the Mauritanians' lack of arms derives its force.

\section{Sketching Our Ongoing Research}

In any case, the analysis of the inferential structure of argument schemes in relation to the standpoint, which we have sketched in the present paper, is necessarily preliminary to the outline of a typology of argument schemes. In fact, although argument schemes can be regrouped in various ways (see the proposals in Toulmin et al. 1984; Walton et al. 2008) it equally emerges that the only proper classification is that based on the "relation of the subject-matter of the premises to that of the conclusion", as formulated by Whatley (1963: 43) in line with the ancient and Medieval tradition. The same principle of classification is assumed by the pragmadialectical perspective (Garssen 2001: 91).

The great enterprise that is still left to the AMT team and to all welcome researchers joining us is the analysis of the ontological-semantic structure of loci. ${ }^{20}$ This analysis is to be performed for each single locus, as it has been proposed in Rigotti's paper on the locus from the final cause (Rigotti 2008); at the same time, this analysis requires a continuous back-and-forth movement between the analysis of the ontologicalsemantic conditions of loci and the empirical reality of argumentative texts where these loci are employed to support real arguments. We are working, also taking into account different contemporary contributions, on the analysis of the semanticontological relations and of the inferential connections activated by them, in order to define their validity criteria (see for some hints Sect. 3).

\footnotetext{
${ }^{20}$ Research on the AMT is currently developing within a series of projects directly or indirectly bound to the doctoral program Argupolis - Argumentation practices in context (www.argupolis.net), financed by the Swiss National Science Foundation - SNFS (Grant: PDAMP1-123089); Eddo Rigotti is the project leader and Sara Greco Morasso is the project coordinator. In particular, one of the research projects in which the AMT is being developed, directed by E. Rigotti, and in which S. Greco Morasso is involved as a consultant, studies argumentation as a tool for resolving conflicts in two quite different contexts: families and publicly listed stock corporations (Grant: PDFMP1-123093). Through the development of the AMT, Eddo Rigotti is contributing to a research project directed by Andrea Rocci and entitled "Modality in argumentation. A semantic-argumentative study of predictions in Italian economic-financial newspapers", also funded by SNFS (Grant: 100012-120740/1). Rigotti is equally involved in another SNFS project led by Andrea Rocci which investigates the argumentative function and rhetorical exploitation of keywords in corporate reporting discourse (Grant: PDFMP1_124845). Finally, Rigotti is conducting a recently approved project studying the argumentative practices adopted by Swiss banks in order to comply with Anti Money Laundering and Counter Terrorism rules in Finance, while, at the same time, preserving the fiduciary relationship with the suspected client (SNFS, Grant: CR11T1_130652/1).
} 
Acknowledgments The authors wish to thank the two reviewers for their important remarks and are particularly grateful to Frans van Eemeren for his precious comments on an earlier version of the manuscript.

\section{References}

Bach, E. 1981. On time, tense and aspect: An essay in English metaphysics. In Radical pragmatics, ed. P. Cole, 63-81. NY: Academic Press.

Barth, E.M., and E.C.W. Krabbe. 1982. From axiom to dialogue. A philosophical study of logics and argumentation. Berlin, New York: de Gruyter.

Bochenski, I.M. (ed.). 1947. Petri Hispani Summulae logicales. Torino: Marietti.

Braet, A.C. 2004. The oldest typology of argumentation schemes. Argumentation 18(1): 127-148.

Braet, A.C. 2005. The common topic in Aristotle's Rhetoric: Precursor of the argumentation scheme. Argumentation 19(1): 65-83.

Christopher Guerra, S. 2008. Themen, Thesen und Argumente zur Position des Italienischen in der viersprachigen Schweiz. Studies in Communication Sciences 8(1): 135-159.

Danesi, M., and A. Rocci. 2009. Global linguistics: An introduction. Berlin: De Gruyter.

De Pater, W.A. 1965. Les topiques d'Aristote et la dialectique platonicienne. Thomasstudien 19. Fribourg: Paulusverlag.

Epstein, R.L. 2001. Predicate logic. Belmont, CA: Wadsworth Thomson Learning.

Filimon, I.A. 2009. Kyosei-an example of cultural keyword argumentatively exploited in corporate reporting discourse. Studies in Communication Sciences 9(2): 131-152.

Garssen, B. 2001. Argument schemes. In Crucial concepts in argumentation theory, ed. F.H. van Eemeren, 81-99. Amsterdam: Sic Sat.

Garssen, B. 2009. Comparing the incomparable: Figurative analogies in a dialectical testing procedure. In Pondering on problems of argumentation, ed. F.H. van Eemeren, and B. Garssen, 133-140. Springer: New York.

Gatti, M.C. 2000. La negazione fra semantica e pragmatica. Milano: ISU.

Greco Morasso, S. 2009. Argumentative and other communicative strategies of the mediation practice, $\mathrm{PhD}$ dissertation, Università della Svizzera italiana, Lugano, $\mathrm{CH}$.

Green-Pedersen, N.J. 1984. The tradition of topics in the middle ages. The commentaries on Aristotle's and Boethius' topics. München, Wien: Philosophia Verlag.

Haack, S. 1978. Philosophy of logics. Cambridge: Cambridge University Press.

Hamblin, C. 1970. Fallacies. London: Methuen.

Hastings, A.C. 1962. A reformulation of the modes of reasoning in argumentation. $\mathrm{PhD}$ dissertation, Northwestern University, Evanston, IL.

Hughes, G.E., and M.J. Cresswell. 1996. A new introduction to modal logic. London, New York: Routledge.

Jackendoff, R. 1983. Semantics and cognition. Cambridge: MIT Press.

Jackendoff, R. 1990. Semantic structures. Cambridge: MIT Press.

Kienpointner, M. 1992. Alltagslogik. Struktur und Funktion von Argumentationsmustern. Stuttgart, Bad Cannstatt: Frommann-Holzboog.

Kienpointner, M. 1997. On the art of finding arguments: What ancient and modern masters of invention have to tell us about the 'Ars inveniendi'. Argumentation 11(2): 225-236.

Klima, G. 2002. English translation of I. Buridani Summulae de dialectica. New Haven: Yale University Press.

Layman, C.S. 2002. The power of logic, 2nd ed. Boston: McGraw-Hill.

Palmieri, R. 2009. Regaining trust through argumentation in the context of the current financial-economic crisis. Studies in Communication Sciences 9(2): 59-78.

Perelman, C., and L. Olbrechts-Tyteca. 1958. Traité de l'argumentation: La nouvelle rhétorique, 5 th ed. Bruxelles: Editions de 1'Université de Bruxelles.

Reinhardt, T. 2003. Marcus Tullius Cicero, Topica. Oxford: Oxford University Press.

Rigotti, E. 2006. Relevance of context-bound loci to topical potential in the argumentation stage. Argumentation 20(4): 519-540.

Rigotti, E., and S. Greco Morasso. 2006. Topics: the argument generator. In Argumentation for financial communication, Argumentum eLearning module, www.argumentum.ch. 
Rigotti, E., and A. Rocci. 2006. Towards a definition of communication context. Foundations of an interdisciplinary approach to communication. In The Communication sciences as a multidisciplinary enterprise, ed. M. Colombetti, 155-180. Studies in Communication Sciences 6 (2), Anniversary issue.

Rigotti, E. 2008. 'Locus a causa finali'. In Proceedings of the IADA Workshop Word meaning in argumentative dialogue. Homage to Sorin Stati, ed. G. Gobber, S. Cantarini, S. Cigada, M. C. Gatti and S. Gilardoni. Special issue of L'analisi linguistica e letteraria XVI 2: 559-576.

Rigotti, E. 2009. Whether and how classical topics can be revived in the contemporary theory of argumentation. In Pondering on problems of argumentation, eds. F. H. van Eemeren, and B. Garssen, 157-178. Op. cit.

Rigotti, E., and S. Greco Morasso. 2009. Argumentation as object of interest and as social and cultural resource. In Argumentation and education: Theoretical foundations and practices, ed. A.N. PerretClermont, and N. Müller-Mirza, 9-66. New York: Springer.

Rigotti, E., and A. Rocci. 2001. Sens-non-sens-contresens. Tentative d'une définition explicative. Studies in Communication Sciences 1(2): 45-80.

Rocci, A. 2006. Pragmatic inference and argumentation in intercultural communication. Intercultural Pragmatics 3(4): 409-442.

Rocci, A. 2008. Modality and its conversational backgrounds in the reconstruction of argumentation. Argumentation 22(2): 165-189.

Ross, W.D. (ed.). 1958. Aristotelis Topica et Sophistici Elenchi. Oxford: Oxford University Press.

Searle, J. 1995. The construction of social reality. N.Y.: Free Press.

Tardini, S. 1997. L'entimema nella struttura logica del linguaggio. L'analisi linguistica e letteraria 2 : 419-440.

Toulmin, S. 1958. The uses of argument. Cambridge: Cambridge University Press.

Toulmin, S., R. Rieke, and A. Janik. 1984. An introduction to reasoning. New York: Macmillan.

Van Eemeren, F.H., and B. Garssen. 2009. Problems of argumentation: An introduction. In Pondering on problems of argumentation. Twenty essays on theoretical issues, ed. F.H. van Eemeren, and B. Garssen, xi-xxi. New York: Springer.

Van Eemeren, F.H., and R. Grootendorst. 1984. Speech acts in argumentative discussions. Dodrecht, NL, Cinnamon, USA: Foris.

Van Eemeren, F.H., and R. Grootendorst. 1992. Argumentation, communication, and fallacies. A pragmadialectical perspective. Hillsdale (NJ) etc.: Erlbaum.

Van Eemeren, F.H., and R. Grootendorst. 2004. A systematic theory of argumentation: The pragmadialectical account. Cambridge: Cambridge University Press.

Van Eemeren, F.H., and P. Houtlosser. 2002. Strategic manoeuvring with the burden of proof. In Advances in Pragma-dialectics, ed. F.H. van Eemeren, 13-28. Amsterdam, Newport News, VA): Sic Sat/Vale Press.

Van Eemeren, F. H. van, and R. Grootendorst. 1999. The fallacies of composition and division. In J.F.A.K.: Essays dedicated to Johan van Benthem on the occasion of his 50th birthday [CD-ROM], ed. J. Gerbrandy, M. Marx, M. de Rijke, and Y. Venema. Amsterdam: Amsterdam University Press. A recent revised version has been published in: van Eemeren, F. H., and B. Garssen. 2009. The fallacies of composition and division revisited. Cogency 1(1): 23-42.

Van Eemeren, F.H., R. Grootendorst, and A.F. Snoeck-Henkemans. 2002. Argumentation: Analysis, evaluation, presentation. Mahwah, NJ: Erlbaum.

Van Eemeren, F.H., R. Grootendorst, and A.F. Snoeck-Henkemans. 2007. Argumentative indicators in discourse: A pragma-dialectical study. New York: Springer.

Vendler, Z. 1957. Verbs and times. The Philosophical Review LXVI: 143-160.

Walton, D. 2005. How to evaluate argumentation using schemes, diagrams, critical questions and dialogues. In Argumentation in dialogic interaction, eds. M. Dascal, F. H. van Eemeren, E. Rigotti, S. Stati, and A. Rocci. Special issue of Studies in Communication Sciences: 51-74.

Walton, D. 2006. Poisoning the well. Argumentation 20(3): 273-307.

Walton, D., and F. Macagno. 2009. Argument from analogy in law, the classical tradition, and recent theories. Philosophy and Rhetoric 42(2): 154-182.

Walton, D., C. Reed, and F. Macagno. 2008. Argumentation schemes. Cambridge: Cambridge University Press.

Whately, R. 1946/1963. Elements of rhetoric, ed. D. Ehninger. Carbondale, IL: Southern Illinois University Press.

Whorf, C. (1997) [1956]. Language, thought, and reality: Selected writings of Benjamin Lee Whorf, ed. J. B. Carrol. Cambridge: Technology Press of MIT. 